\title{
PERBANDINGAN UNJUK KERJA DAN KONSUMSI BAHAN BAKAR ANTARA MOTOR YANG MEMPERGUNAKAN KOIL STANDAR DAN BUSI STANDAR DENGAN MOTOR YANG MEMPERGUNAKAN KOIL RACING DAN BUSI RACING MENGGUNAKAN BAHAN BAKAR PERTAMAX
}

\author{
RIKI CANDRA PUTRA \& ANDRI SUHENDRI \\ Program Studi Teknik Mesin, Fakultas Teknik, Universitas Muhammadiyah Tangerang \\ Jl. Perintis Kemerdekaan I/33 Cikokol-Tangerang \\ E-mail: riki.candra@gmail.com; andri27041@gmail.com
}

\begin{abstract}
ABSTRAK
Tujuan dari penelitian ini adalah untuk mengetahui performa mesin dengan membandingkan sistem pengapian antara penggunaan koil standar dan busi standar dengan koil racing dan busi racing dengan bahan bakar pertamax. Metode penelitian yang dipergunakan adalah eksperimen. Teknik analisis data menggunakan analisis deskriptif yaitu mengamati dan mencatat hasil pengujian kemudian menyimpulkan dalam bentuk tabel dan grafik. Pengujian torsi dan daya dilakukan pada mesin Vixion New 150 cc tahun 2018 menggunakan dynamometer dan alat ukur buret digunakan untuk pengujian konsumsi bahan bakar. Pengambilan data dilakukan pada putaran $5000 \mathrm{rpm}, 6000 \mathrm{rpm}, 7000 \mathrm{rpm}, 8000 \mathrm{rpm}$ dan $9000 \mathrm{rpm}$. Hasil pengujian menunjukkan adanya perbedaan daya, torsi dan konsumsi bahan bakar yang dihasilkan oleh kedua coil dan busi. Untuk daya, dan torsi yang dihasilkan coil racing dan busi racing memiliki nilai yang lebih tinggi jika dibandingkan dengan coil standar dan busi standar dan untuk konsumsi bahan bakar coil racing dan busi racing memiliki nilai yang lebih rendah dibandingkan dengan coil standar dan busi standar, yang artinya konsumsi bahan bakar coil racing dan busi racing lebih irit jika dibandingkan dengan coil standar dan busi satandar, sehingga dari penelitian yang sudah dilakukan pada motor Yamaha Vixion New 150 cc dapat disimpulkan ternyata ada kenaikan daya dan torsi yang dihasilkan pada motor yang menggunakan coil racing dan busi racing dan untuk konsumsi bahan bakar terjadi penurunan pada motor yang menggunakan coil racing dan busi racing.
\end{abstract}

Kata Kunci: bahan bakar, koil, pengapian, racing, busi

\section{PENDAHULUAN}

Perkembangan teknologi pada saat ini yang semakin pesat, mendorong manusia untuk selalu menciptakan inovasi. Perkembangan teknologi juga terjadi pada bidang otomotif, khususnya pada sistem pengapian pada sepeda motor. Sistem pengapian merupakan salah satu dari sekian banyak komponen sepeda motor yang paling sering mengalami perkembangan. Dikarenakan untuk memperoleh unjuk kerja mesin yang baik dibutuhkan sistem pengapian yang baik pula.

Sistem pengapian merupakan sistem yang sangat penting pada sepeda motor. Menurut Jama \& Wagino (2008: 165), sistem pengapian pada motor bensin berfungsi mengatur proses pembakaran campuran bensin dan udara di dalam silinder sesuai waktu yang sudah ditentukan yaitu pada akhir langkah kompresi. Sistem pengapian ini sangat berpengaruh pada daya, torsi dan konsumsi bahan bakar yang dibangkitkan oleh mesin tersebut.
Sistem pengapian khususnya pada motor bensin 4 langkah telah mengalami banyak penyempurnaan. Pada saat awal sepeda motor mulai diproduksi sistem pengapian pada motor bensin menggunakan sistem pengapian konvensional (platina). Sistem pengapian konvensional merupakan sistem pengapian yang menggunakan platina (contact breaker) untuk memutus dan menghubungkan tegangan baterai ke kumparan primer.

Dengan usaha memperhatikan dan menyempurnakan parameter-parameter yang mempengaruhinya, salah satu diantaranya adalah pengubahan sistem pengapian, hal ini mempunyai maksud agar pembakaran di dalam ruang bakar dapat terjadi pembakaran yang sempurna, dengan pembakaran yang sempurna diharapkan unjuk kerja dari mesin tersebut dapat meningkat tanpa mengurangi efisiensi dari mesin tersebut.

Penggantian koil standar dan busi standar dengan tipe racing merupakan salah satu cara agar 
mendapatkan pengapian yang lebih baik sehingga diharapkan terjadi pembakaran yang sempurna di ruang bakar.

Maka Terdorong keingintahuan terhadap pengaruh penggantian koil dan busi pada mesin sepeda motor, maka peneliti tertarik untuk melakukan penelitian dengan judul "Perbandingan Unjuk Kerja dan Konsumsi Bahan Bakar Antara Motor yang Mempergunakan koil standar dan busi standar dengan Motor yang Mempergunakan koil racing dan busi racing menggunakan bahan bakar pertamax".

Motor bakar adalah suatu mesin yang mengkonversi energi dari energi kimia yang terkandung pada bahan bakar menjadi energi mekanik pada poros motor bakar, jadi daya yang berguna akan langsung dimanfaatkan sebagai penggerak adalah daya pada poros (Raharjo dan Karnowo, 2008:93).

Awal atau permulaan pembakaran sangat diperlukan karena, pada motor bensin pembakaran tidak bisa terjadi dengan sendirinya. Pembakaran campuran bensin dan udara yang dikompresikan terjadi di dalam ruang bakar (silinder blok) setelah busi memercikkan bunga api, sehingga diperoleh tenaga akibat pemuaian gas (eksplosif) hasil pembakaran, mendorong piston ke posisi TMB (titik mati bawah) menjadi langkah usaha. Agar busi dapat memercikkan bunga api dengan tepat, maka diperlukan suatu sistem yang bekerja secara akurat.

Sistem pengapian terdiri dari berbagai komponen, yang bekerja bersama-sama dalam waktu yang sangat cepat dan singkat. Menurut Haryono (1997:29). Bunga api pada busi berasal dari arus listrik tegangan tinggi di mana arus ini mengalir pada waktu tertentu, jadi sewaktu arus mengalir busi memercikan bunga api dan sewaktu tidak ada aliran, busi mati.

Koil pengapian merubah sumber tegangan rendah dari baterai 12 Volt menjadi tegangan tinggi ribuan volt yang diperlukan untuk menghasilkan loncatan bunga api yang kuat pada celah busi dalam sistem pengapian (Jama \& Wagino, 2008b: 174).

Menurut Jama \& Wagino (2008b: 201) koil tersebut menaikkan tegangan tinggi mencapai lebih $10 \mathrm{KV}$. Menurut Oetomo dkk (2014: 48) perbedaan antara koil standard dan koil racing yaitu kumparan primer dan sekunder pada koil racing lebih lebih banyak daripada koil standard. Hal ini yang menyebabkan tegangan yang dihasilkan koil racing lebih besar dibandingkan koil standard.

Busi berfungsi untuk meloncatkan bunga api listrik tegangan tinggi sehingga mampu menyalakan campuran bahan bakar dan udara yang dimampatkan di ruang bakar (Kristanto, 2015: 181).

\section{METODOLOGI PENELITIAN Diagram alir penelitian}

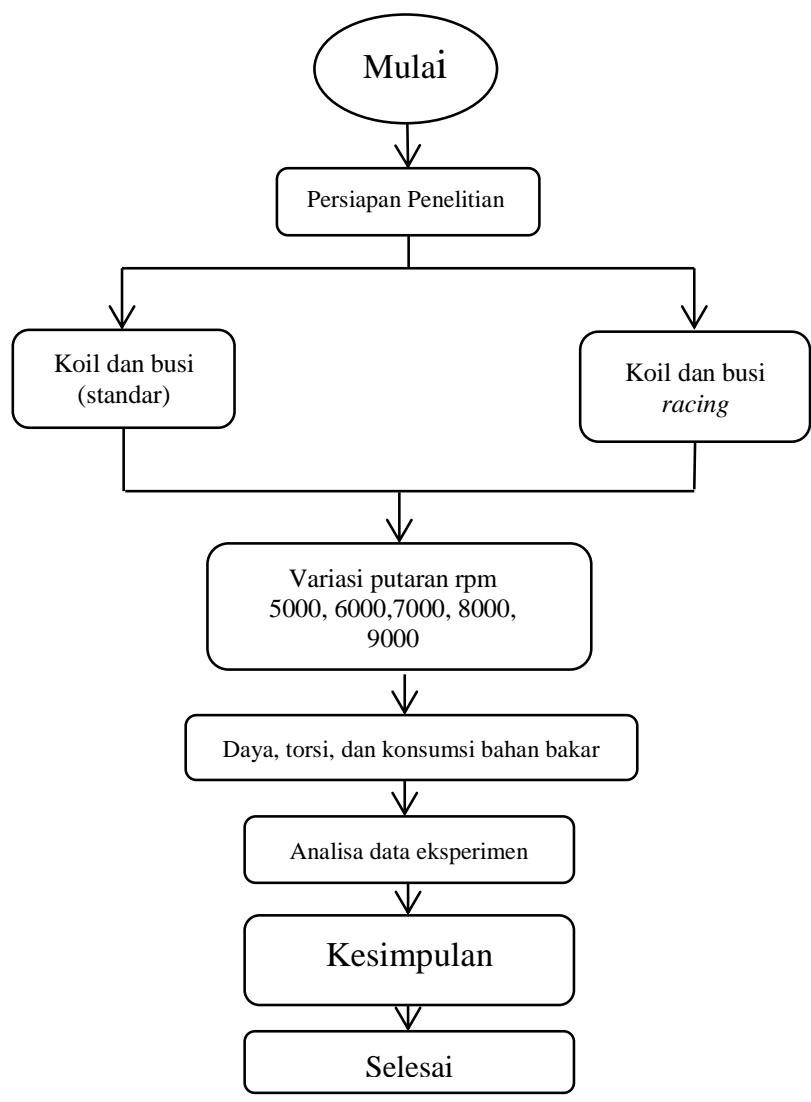

Gambar 1 Diagram alir

Sumber data yang diperlukan dalam penelitian ini terdiri dari dua data, antara lain:

\section{Data Primer}

Data primer merupakan data penelitian yang didapatkan secara langsung dari eksperimen dengan melalukan percobaan koil standar dan busi sdtandar dengan koil racing dan busi racing. Data primer dalam penelitian ini diperoleh dari hasil pengamanatan peneliti terhadap daya, torsi, dan pemakaian bahan bakar.

\section{Data Sekunder}

Data sekunder adalah data yang diperoleh dari jurnal dan buku..

Teknik analisis data yang dipakai dalam penelitian menggunakan teknik analisis deskriptif yaitu mengamati dan mencatat secara langsung hasil 
eksperimen kemudian menyajikannya dalam bentuk tabel dan polygon sesuai hasil penelitian yang telah dilakukan. Data yang dihasilkan yaitu daya (hp), torsi (Nm) dan konsumsi bahan bakar (cc/menit).

Penggambaran dari fenomena yang terjadi selama penelitian ditunjukan dalam tabel dan polygon yang menggambarkan perbedaan antara koil standar dan busi standar dengan koil racing dan busi racing terhadap daya, torsi dan konsumsi bahan bakar pada sepeda motor Yamaha Vixion New 150cc Tahun 2018.

\section{Waktu dan Tempat Penelitian}

Pelaksanaan eksperimen dan pengambilan data dalam peneltian ini dilakukan pada:

Hari : Selasa

Tanggal : 28 Agustus 2018

Tempat : Bengkel Ultra Speed Racing di Jl.daan Mogot Raya Km.11 No.06, RT.07/RW.06, Kedaung Kali Angke, Cengkareng, Jakarta Barat.

\section{Bahan Penelitian}

$>$ Sepeda motor dengan merk YAMAHA VIXION NEW $150 \mathrm{cc}$ tahun 2018 dengan spesifikasi sebagai berikut :

Tipe mesin : Liquid cooled 4-stroke, SOHC

Diameter x Langkah piston : $57 \mathrm{~mm}$ x $58,7 \mathrm{~mm}$

Volume silinder : $150 \mathrm{cc}$

Perbandingan kompresi : $10.4: 1$

Daya maksimum : $12.2 \mathrm{KW} / 8500 \mathrm{RPM}$

Torsi maksimum : $14.5 \mathrm{Nm} / 7500 \mathrm{RPM}$

Sistem bahan bakar : injection

$>$ Bahan bakar jenis pertamax.

$>$ Koil dan busi (standar).

$>$ Koil dan busi racing

\section{Alat Peralatan Penelitian}

Alat yang digunakan saat penelitian yaitu dynamometer, stopwatch, burre ukur, compression tester, dan tool set.

Langkah-langkah pengujian sebagai berikut :

a. Menaikkan dan memasang sepeda motor pada alat uji dynamometer.

b. Memasang selang buret tetes pada lubang masuk bahan bakar. Kemudian mengisi buret tetes dengan pertamax.

c. Memanaskan motor hingga mendekati suhu kerja mesin selama (2-3 menit) yaitu $\pm 80^{\circ} \mathrm{C}$.

d. Setelah proses pemanasan di atas selesai, memindahkan transmisi ke gigi 4. Dikarenakan pada posisi gigi 4 power band lebih luas atau besar dan tenaga puncak lebih cepat terasa.

e. Mengatur putaran mesin dengan membuka katup gas hingga pada tachometer digital menunjukkan angka $5000 \mathrm{rpm}$. Setelah mencapai $5000 \mathrm{rpm}$ kemudian melakukan pengambilan data pengukuran daya, torsi dan konsumsi bahan bakar.

f. Mencatat data besar konsumsi bahan bakar bersamaan dengan pengujian daya dan torsi, konsumsi bahan bakar diukur banyak bahan bakar bahan bakar yang digunakan oleh sepeda motor dalam waktu 1 menit dengan menggunakan alat buret ukur dan stopwatch.

g. Setelah mencatat data yang diperoleh, kemudian melakukan pengamatan juga pada putaran mesin $6000 \mathrm{rpm}$ sampai $9000 \mathrm{rpm}$. Setelah selesai mencatat data, kurangi putaran mesin sedikit demi sedikit hingga menit untuk pendinginan mesin.

h. Pengujian kembali dilakukan dengan mengulang langkah-langkah pengujian awal dengan menggunakan koil dan busi racing.

\section{Hasil Pengambilan data}

Berikut adalah data-data yang diambil dari pengujian:

Tabel 1 Hasil pengujian

\begin{tabular}{|c|c|c|c|c|c|c|}
\hline \multirow[b]{2}{*}{ Rpm } & \multicolumn{3}{|c|}{$\begin{array}{l}\text { KOIL DAN BUSI } \\
\text { STANDAR }\end{array}$} & \multicolumn{3}{|c|}{$\begin{array}{c}\text { KOIL DAN BUSI } \\
\text { RACING }\end{array}$} \\
\hline & $\begin{array}{l}\text { Daya } \\
\text { (Hp) }\end{array}$ & $\begin{array}{l}\text { Torsi } \\
(\mathrm{Nm})\end{array}$ & $\begin{array}{c}\text { Laju } \\
\text { Konsumsi } \\
\text { Bahan } \\
\text { Bakar } \\
\text { (cc/mnt) }\end{array}$ & $\begin{array}{l}\text { Daya } \\
\text { (Hp) }\end{array}$ & $\begin{array}{l}\text { Torsi } \\
(\mathrm{Nm})\end{array}$ & $\begin{array}{c}\text { Laju } \\
\text { Konsumsi } \\
\text { Bahan } \\
\text { Bakar } \\
\text { (cc/mnt) }\end{array}$ \\
\hline 5000 & 4.8 & 6.1 & 15,6 & 5.1 & 7.3 & 14,7 \\
\hline 6000 & 8.0 & 9.5 & 16.7 & 8.2 & 9.7 & 16.1 \\
\hline 7000 & 10.2 & 10.4 & 18.5 & 10.4 & 10.5 & 17.8 \\
\hline
\end{tabular}


Motor Bakar: Jurnal Teknik Mesin Universitas Muhammadiyah Tangerang, $\quad$ Vol. $\quad$ P-ISSN: 2549-5038

2, No. 1, Juli-Desember, 2018

E-ISSN: 2580-4979

\begin{tabular}{|l|l|l|l|l|l|l|}
\hline 8000 & 11.6 & 10.2 & 19.8 & 11.7 & 10.3 & 19.2 \\
\hline 9000 & 11.76 & 9.2 & 22.8 & 12.00 & 9.3 & 21.5 \\
\hline
\end{tabular}

\begin{tabular}{|l|l|l|}
7000 & 0.28 & 17.8 \\
\hline 8000 & 0.26 & 19.2 \\
\hline 9000 & 0.23 & 21.5 \\
\hline
\end{tabular}

\section{HASIL DAN PEMBAHASAN}

Dengan mempergunakan mesin uji YAMAHA XIXION NEW $150 \mathrm{cc}$. Parameter yang diteliti adalah daya, torsi dan laju konsumsi bahan bakar dengan perlakuan merubah koil standar bawaan pabrik dengan koil racing USR (ultra speed racing).

Pengambilan data dilakukan dalam tiga variasi putaran mesin yaitu putaran $4000 \mathrm{rpm}, 6000 \mathrm{rpm}$, $7000 \mathrm{rpm}, 8000 \mathrm{rpm}$ dan $9000 \mathrm{rpm}$, sehingga akan diketahui seberapa besar perbedaan hasil daya, torsi yang lebih signifikan dari tiap-tiap koil, serta berapa banyak bahan bakar yang digunakan untuk tiap-tiap koil. Hasil pengujian daya, torsi dan konsumsi bahan bakar dapat dilihat pada pada tabel 1 .

Berikut ini adalah tabel perbandingan waktu dalam satuan menit yang diperlukan sepeda motor untuk menghabiskan volume bensin sebesar $5 \mathrm{cc}$.

Tabel 2. Konsumsi bahan bakar motor yang menggunakan koil standar

\begin{tabular}{|c|c|c|}
\hline RPM & $\begin{array}{c}\text { Lama waktu } \\
\text { menghabiskan 5cc } \\
\text { (menit) }\end{array}$ & $\begin{array}{c}\text { Laju } \\
\text { Konsumsi } \\
\text { Bahan Bakar } \\
\text { (cc/mnt) }\end{array}$ \\
\hline 5000 & 0.32 & 15,6 \\
\hline 6000 & 0.3 & 16.7 \\
\hline 7000 & 0.27 & 18.5 \\
\hline 8000 & 0.25 & 19.8 \\
\hline 9000 & 0.22 & 22.8 \\
\hline
\end{tabular}

Tabel 3. Konsumsi bahan bakar motor yang menggunakan koil racing

\begin{tabular}{|c|c|c|}
\hline RPM & $\begin{array}{c}\text { Lama waktu } \\
\text { menghabiskan 5cc } \\
\text { (menit) }\end{array}$ & $\begin{array}{c}\text { Laju } \\
\text { Konsumsi } \\
\text { Bahan Bakar } \\
\text { (cc/mnt) }\end{array}$ \\
\hline 5000 & 0.34 & 14,7 \\
\hline 6000 & 0.31 & 16.1 \\
\hline
\end{tabular}

\section{Pembahasan}

1. Analisis perbandingan yang dihasilkan pada

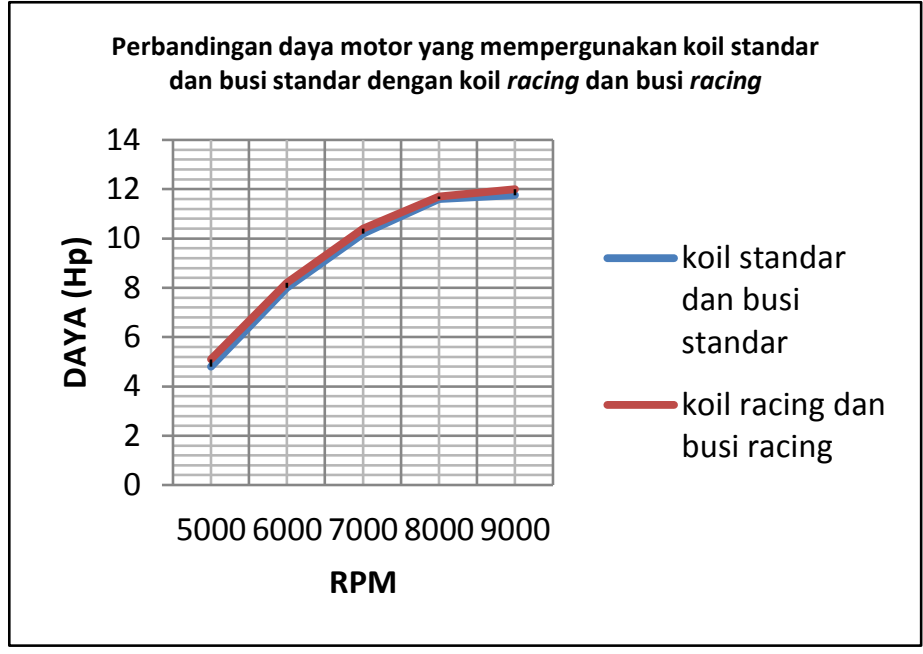

motor yang mempergunakan koil standar dan busi standar dengan koil racing dan busi racing untuk lebih jelasnya dapat dilihat pada grafik di bawah ini.

\section{Gambar 2 Grafik Perbandingan Daya}

Berdasarkan data yang diperoleh dari penelitian yang telah dilakukan, menunjukkan bahwa terdapat perbedaan daya yang diperoleh pada motor yang mempergunakan koil standar dan busi standar dengan motor yang mempergunakan koil racing dan busi racing. Gambar grafik di atas menunjukkan bawah hasil penelitian menunjukkan daya yang dihasilkan pada koil racing dan busi racing memiliki nilai yang lebih tinggi jika dibandingkan dengan koil standar dan busi standar. Perbedaan daya yang dihasilkan oleh kedua jenis koil dan busi ini dikarenakan perbedaan besar pengapian yang dihasilkan koil dan busi tersebut.

Perbedaan besarnya pengapian dikarenakan ada perbedaan komponen yang terdapat di dalam koil dan busi, sehingga membuat tegangan yang dihasilkan oleh koil dan busi menjadi berbeda, karena tegangan yang dihasilkan berbeda sehingga percikan bunga api yang dihasilkan koil dan busi pun menjadi 
berbeda, sehingga daya yang dihasilkan pun menjadi berbeda.

Daya yang dihasilkan pada motor sangat dipengaruhi oleh besarnya bunga api yang dihasilkan oleh busi, karena semakin besar pengapian yang dihasilkan maka pembakaran yang dihasilkan pada silinder menjadi lebih baik.

Dari penelitian yang telah dilakukan pada sepeda motor Yamaha Vixion New 150cc dapat disimpulkan torsi yang dihasilkan koil racing dan busi racing lebih tinggi dari pada koil standar dan busi standar.

2. Analisis perbandingan torsi $(\mathrm{Nm})$ yang dihasilkan pada motor yang mempergunakan koil dan busi standar dan koil dan busi racing untuk lebih jelasnya dapat dilihat pada grafik di bawah ini

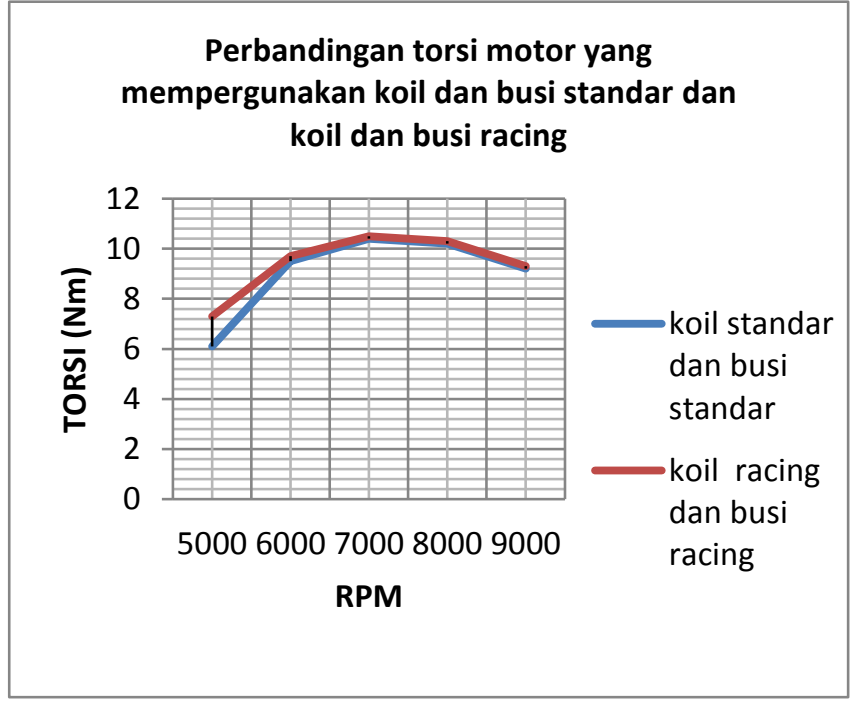

Gambar 3 Grafik Perbandingan Torsi

Berdasarkan data yang diperoleh dari penelitian yang telah dilakukan, menunjukkan bahwa terdapat perbedaan torsi yang diperoleh pada motor yang mempergunakan koil standar dan busi standar dengan motor yang mempergunakan koil racing dan busi racing.

Gambar grafik di atas menujukkan bahwa hasil penelitian, menujukkan torsi yang dihasilkan pada koil racing dan busi racing memiliki nilai yang lebih tinggi jika dibandingkan dengan koil standar dan busi standar. Perbedaan torsi yang diperoleh dari kedua buah koil dan busi dikarenakan perbedaan besar pengapian yang dihasilkan dari kedua buah koil dan busi tersebut.

Perbedaan besarnya pengapian dikarenakan ada perbedaan komponen yang terdapat di dalam koil dan busi, sehingga membuat tegangan yang dihasilkan oleh koil dan busi menjadi berbeda, karena tegangan yang dihasilkan berbeda sehingga percikan yang dikeluarkan koil dan busi pun menjadi berbeda.

Besarnya pengapian yang dihasilkan oleh koil dan busi sangat mempengaruhi besar kecilnya torsi yang dihasilkan pada sepeda motor yang menggunakan koil standar dan busi standar dengan koil racing dan busi racing, karena hal ini berhubungan dengan gaya tekan pembakaran yang dihasilkan pada silinder piston.

3. Analisis perbandingan laju bahan bakar yang dihasilkan pada motor yang mempergunakan koil standar dan busi standar dengan koil racing dan busi racing untuk lebih jelasnya dapat dilihat pada tabel dan grafik di bawah ini.

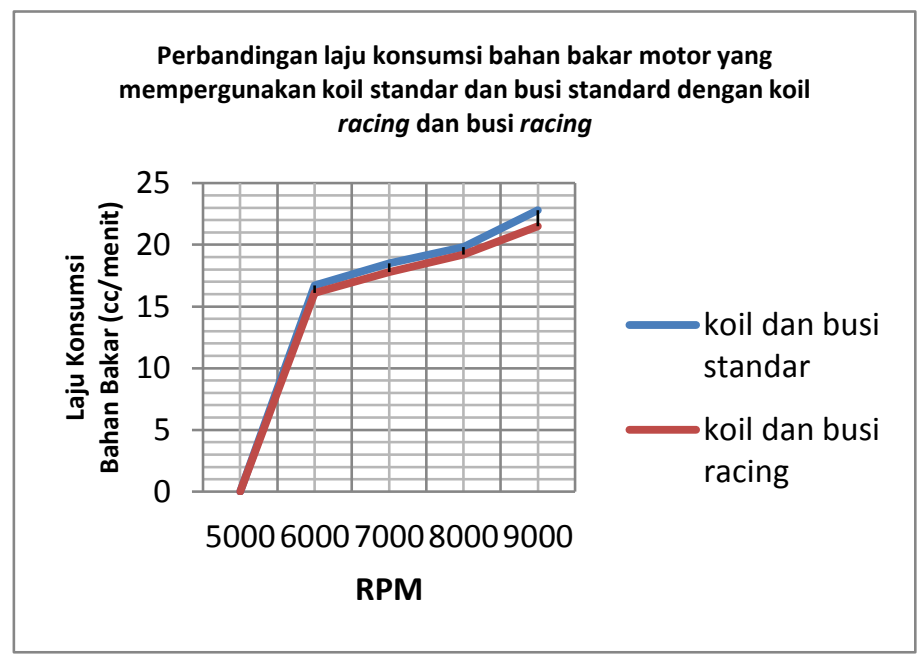

\section{Gambar 4 Grafik Perbandingan Konsumsi Bahan Bakar}

Berdasarkan data yang diperoleh dari penelitian yang telah dilakukan, menunjukkan bahwa terdapat perbedaan konsumsi bahan bakar yang diperoleh pada motor yang mempergunakan koil standar dan busi standar dengan koil racing dan busi racing.

Gambar grafik di atas menujukkan bahwa hasil penelitian, menujukkan konsumsi bahan bakar yang dihasilkan pada koil dan busi racing memiliki nilai yang lebih rendah jika dibandingkan dengan koil dan busi standar.

Perbedaan laju konsumsi bahan bakar yang diperoleh dari kedua buah koil dan busi dikarenakan pengapian yang dihasilkan oleh koil dan busi racing 
lebih besar dari pada standard. Besarnya pengapian dikarenakan ada perbedaan komponen yang terdapat di dalam koil dan busi sehingga membuat tegangan yang dihasilkan oleh koil dan busi menjadi berbeda, karena tegangan yang dihasilkan berbeda sehingga percikan yang dikeluarkan koil dan busi pun menjadi berbeda.

Besarnya pengapian yang dihasilkan oleh koil dan busi sangat mempengaruhi konsumsi bahan bakar, karena dengan pengapian yang lebih baik (besar) campuran bahan bakar yang terdapat di ruang bakar akan terbakar dengan sempurna, sehingga tenaga yang dihasilkan akan lebih besar, karena lebih besar maka konsumsi bahan bakar akan lebih irit.

Apabila pengapian yang kecil (buruk) maka campuran bahan bakar yang terdapat diruang bakar akan terbakar tidak sempurna, sehingga tenaga yang dihasilkan tidak maksimal, dan tenaga yang dihasilkan pun tidak maksimal sehingga konsumsi bahan bakar akan lebih banyak (boros).

\section{KESIMPULAN}

Pengaruh mengganti koil dan busi terhadap daya yang dihasilkan akan terjadi kenaikan, pengaruh mengganti coil dan busi terhadap torsi yang dihasilkan terjadi kenaikan, dan pengaruh mengganti coil dan busi terhadap konsumsi bahan bakar yang dihasilkan terjadi penurunan karena semakin baik percikan bunga api yang dihasilkan busi maka daya dan torsi yang dihasilkan motor akan meningkat.

Untuk konsumsi bahan bakar justru terjadi sebaliknya, yaitu semakin baik pengapian yang dihasilkan oleh busi maka bahan bakar yang diperlukan akan lebih sedikit.

\section{DAFTAR PUSTAKA}

Arends, BPM \& H, Berenschot. 1980.Motor Bensin. Jakarta: PT. Erlangga.

Badrawada, I Gusti Gde. 2008. Pengaruh Perubahan Sudut Pengapian Terhadap Prestasi Mesin 4Langkah. Forum Teknik Vol.32, No.3 Hal 221231.

Daryanto. 2002. Teknik Reparasi dan Perawatan Sepeda Motor.

Jakarta : Bumi Aksara.

Haryono, G. 1997. Uraian Praktis Mengenal Motor Bakar. Semarang: Aneka Ilmu
Hidayat, Wahyu. 2012. Motor Bensin Modern. Jakarta: Rineka Cipta

Jama, Jalius dan Wagino. 2008. Teknik Sepeda Motor Jilid 1. Jakarta: Direktorat Pembinaan Sekolah Menengah Kejuruan, Direktorat Jenderal Manajemen Pendidikan Dasar dan Menengah, Departemen Pendidikan Nasional.

Soenarta, Nakoela dan Sochi Furuhama. 1995. Motor Serba Guna. Jakarta : Pradnya Paramita.

Tirtoatmodjo, Raharjo, Wiliayanto \& Slamet Basuki. 2000. Peningkatan Unjuk Kerja Motor Bensin Empat Langkah dengan Penggunaan Busi Dua Elektrode dan Busi Tiga Elektrode. Jurnal Teknik Mesin Vol. 2, No. 1 Hal, 15-21.

Bakar Honda GX-160. Jurnal Ilmiah Bidang SainsTeknologi Murni Disiplin dan Antar Disiplin Vol. 1 No.14. TahunVIII maret 2014

Oetomo, JAS dkk. 2014. Analisis Penggunaan Koil Racing Terhadap Daya Pada Sepeda Motor. Jurnal Teknik Mesin, Tahun 22, No. 1, April 2014, hal 46-56

Pertamina. 2007. Material Safety Data Sheet Gasoline 92. Jakarta: PT. Pertamina (Persero)

Raharjo, WD dan Karnowo. 2008. Mesin Konversi Energi. Semarang: UNNES PRESS

Rizal, MS. 2013. Konversi Energi. Jakarta: Direktorat Pembinaan Sekolah Menengah Kejuruan, Direktorat Jenderal Manajemen Pendidikan Dasar dan Menengah, Departemen Pendidikan Nasional.

Adnyana, IWB. 2009. Upaya Peningkatan Unjuk Kerja Mesin dengan Menggunakan Sistem Pengapian Elektronis pada Kendaraan Bermotor. Jurnal Ilmiah Teknik Mesin CakraM Vol. 3 No. 1, April 2009 hal 87-92

Arends, BMP dan Berenschot H. 1980. Motor Bensin. Jakarta: Erlangga

Badan Pusat Statistika. 2014. Statistika Transportasi Darat. http: //www.bps.go.id/website/pdf_publikasi/Statisti k-Transportasi--Darat-- 2014.pdf. diakses hari Rabu, 24 februari 2016 14.36 WIB

Badrawada, IGG. 2008. Pengaruh Perubahan Sudut PcngapianTcrhadap Prestasi Mesin Motor 4 Langkah. Jurnal Forum Teknik Vol. 32, No.3, September 2008. Hal 221-231 